\title{
NOVOS ECOLOGISMOS: POR UMA LÓGICA AMBIENTAL CONTRA-HEGEMÔNICA - TRIBUTO A ORDEP SERRA
}

\author{
New ecologisms for an environmental logic counter-hegemonic: tribute to \\ Ordep Serra
}

\begin{abstract}
Julio Cesar de Sá da Rocha
Pós-Doutor em Antropologia pela UFBA. Mestre e Doutor em Direito pela PUC SP. Professor da Faculdade de Direito da UFBA Diretor da Faculdade de Direito da UFBA. E-mail: E-mail: juliorochaufba@gmail.com. Lattes: http:/ / lattes.cnpq.br/7066612031979191
\end{abstract}

\author{
Roberta Neri da Silva \\ Mestre em Geografia pela Universidade Federal da \\ Bahia. Bacharel em Diteito e em Jornalismo pela UFBA. \\ E-mail: rbda.ufba@gmail.com. Lattes: http://lattes.cnpq. \\ br/7428466554823464
}

\begin{abstract}
Resumo
O artigo propõe análise dos novos ecologismos e a construção contra-hegemônica. Foi explicitado no texto as correntes do ecologismo com influência do modelo norte-americano e durante o século XX, o estabelecimento do modelo conservacionista no Brasil. Por sua vez, a implementação de parques gerou conflitos diretamente relacionados à desapropriação e à gestão do território de populações tradicionais. De outra forma, existe discurso desenvolvimentista do Estado e atuação massiva do mercado privado. Em contrapartida, é possível apontar movimentos sociais que propõem outra forma de compreender a relação homem/natureza, superando a separação consagrada pela perspectiva ambiental dominante ou conectada exclusivamente com os lucros. As comunidades tradicionais quando envolvidas em conflitos territoriais têm, portanto, lutado para provar o valor do lugar, do meio ambiente, da territorialidade contra a coisificação do lugar presente nos processos capitalistas desenvolvimentistas. Enfim, emerge um ambientalismo insurgente representado pelas comunidades e na academia incorporando concepções emancipatórias pós-coloniais e decoloniais. O artigo oferece tributo ao intelectual Ordep Serra por sua concepção emancipatória em defender direitos das comunidades com valorização do candomblé com seu ambientalismo tradicional de ancestralidade negra.
\end{abstract}

Palavras-Chave: Ecologismos; lógica ambiental; contra-hegemonia

\section{Abstract}

The article proposes an analysis of the new ecologisms and the counter-hegemonic construction. The currents of ecology influenced by the North American model were explained in the text and during the 20th century the establishment of the conservationist model in Brazil. In turn, the implementation of parks generated conflicts directly related to the expropriation and management of the territory of traditional populations. Otherwise, there is a developmentalist discourse of the State and a massive performance of the private market. On the other hand, it is possible to point out social movements that propose another way of understanding the relation man / nature, overcoming the separation consecrated by the dominant environmental perspective or connected exclusively with the profits. Traditional communities, when involved in territorial conflicts, have therefore struggled to prove the value of the place, the environment, and territoriality against the reification of the present place in the developmentalist capitalist processes. In short, emerges an insurgent environmentalism represented by communities and academia incorporating postcolonial and decolonial emancipatory conceptions. The article offers tribute to the intellectual Ordep Serra for his emancipatory conception emancipatory 
conception in defending the rights of the communities with valorization of candomble with its traditional environmentalism of black ancestry.

KEY-WORD: Ecologism; environmental logic; counter-hegemonic

\section{INTRODUÇÃo}

Presente no debate mundial desde a segunda metade do séc. XX, a crise ambiental foi perpassada pela implementação de algumas políticas ambientais calcadas em teorias biocêntricas que, em um viés equivocado, compreendem o homem numa relação dicotômica e separada do seu entorno. Assim, a concepção de que o meio ambiente natural deve se manter o menos tocado possível pelo ser humano foi profundamente difundida a partir da experiência 'conservacionista norteamericana". Posteriormente, o desenvolvimento sustentável, em sua forma dominante, ocupou as prateleiras do mercado verde e do discurso estatal como a solução apaziguadora entre a produção, o consumo, o desenvolvimento e o ambientalismo.

Durante o século XX, o estabelecimento do modelo conservacionista no Brasil foi utilizado como uma das principais estratégias da proteção ambiental, sendo criados mais de setenta parques até a década de 80 (MARTINS, 2012). Em 1988, este sistema foi reafirmado pela Constituição da República Federativa do Brasil (CF/88) e, posteriormente, em 2000, implantado com o Sistema Nacional de Unidades de Conservação (SNUC). Nesta etapa, estabeleceram-se as chamadas categorias de Proteção Integral, que permitem a criação de determinadas unidades de conservação sem a presença humana, como parque, reserva biológica e estação ecológica. Excepcionalmente, permite-se nas unidades de Proteção Integral, dos tipos Monumento Natural e Refúgio da Vida Silvestre, havendo compatibilização entre os objetivos da unidade, a utilização da terra e dos recursos naturais do local pelos proprietários.

A implementação de parques no Brasil gerou, e ainda gera, conflitos diretamente relacionados à desapropriação e à gestão do território de algumas populações tradicionais , que ocorreram de estar situadas em trechos preservados e de biodiversidade.

Ao lado desta forma de implementar políticas ambientais, o desenvolvimento sustentável fez-se presente no discurso desenvolvimentista do Estado, além de massivamente representado no mercado privado. Programas como o PAC (Programa de Aceleração do Crescimento), criado em 2007, são afirmados enquanto formas de se acessar o desenvolvimento econômico e sustentado, independentemente das comunidades atingidas pelas grandes obras viárias e energéticas.

Em contrapartida, é possível apontar movimentos sociais que propõem outra forma de compreender a relação homem/natureza, superando a separação consagrada pela perspectiva ambiental dominante ou conectada exclusivamente com os lucros. Estas experiências contrapõem os paradigmas ambientalistas hegemônicos citados e demonstram que o discurso universalista, uníssono, de cima para baixo, tanto é reducionista, quanto silenciador das diferenças. Para expor tal análise, o presente capítulo segue um caminho de revisão de literatura, ao mesmo tempo em que traz uma reflexão sobre os movimentos insurgentes e contrários à lógica dominante do desenvolvimento sustentável e do conservacionismo. 


\section{Ahegemonia do conservacionismo e o ecologismo dos pobres como proposta CONTRA-HEGEMÔNICA}

O conservacionismo é um movimento que ganha força a partir da criação do Parque de YellowStone, em 1872, nos EUA. Baseado no estabelecimento de parques ou reservas naturais desabitados, o conservacionismo levantou uma bandeira "a qual foi sendo imposta a outros países e sociedades com características ecológicas e sociais diferentes" (DIEGUES, 2000, p. 3). Apesar das vantagens de manter espécies endêmicas e impedir o avanço do desmatamento/ degradação sobre áreas que merecem proteção diante de especificidades naturais, as restrições de manejo impostas pelos parques acaba por criar conflitos com os moradores das áreas destinadas a esta proteção.

Em países como o Brasil e a Índia, o estabelecimento de parques saiu como a compra de um produto importado e, na maioria das vezes, quem pagou a conta das externalidades foram as populações tradicionais e indígenas que habitavam os espaços escolhidos para tal forma de proteção ambiental. O resultado era (e ainda é) a desocupação coercitiva destas populações, quando estas não resistiam e partiam para o embate e luta pelo direito ao território. Várias destas perspectivas ganharam força entre biólogos de diversos países, estabelecendo uma neocolonização, pois, da mesma forma que os colonizadores julgavam representar os interesses dos colonizados, os biólogos da conservação consideram-se os defensores da natureza nos países subdesenvolvidos (DIEGUES, 2000, p. 18). A hegemonia desta corrente se expressa, portanto, conforme a compreensão gramsciniana, dentro de uma unidade intelectual que combina filosofia e prática e que se manifesta através da dominação, controle da sociedade e dos instrumentos estatais (GRAMSCI, 1999).

Diante deste contexto, novos ecologismos surgem a partir dos movimentos sociais com vistas a abrir caminhos nas discussões que atrelem ambientalismo e igualdade, controle comunal dos meios de produção (e não estatal), entre outros. A corrente do ecologismo dos pobres, assim denominada por Joan Martínez Alier (2007), figura como um movimento social dos pobres relacionados à luta por sua própria sobrevivência humana. Alier (2007) propõe uma classificação didática entre os movimentos ambientalistas, dividindo-os em três correntes: o culto ao silvestre, o evangelho da coeficiência e o ecologismo dos pobres. Com diversos elementos em comum, essas correntes se diferenciam geralmente pelo pensamento ético-científico que as guiam nas lutas ambientais.

Para rapidamente expor as correntes, o culto ao silvestre parte em defesa da natureza intocada, com base científica na biologia da conservação, com o objetivo de preservar a biodiversidade, possibilitar a contemplação e criar parques e reservas sem a presença humana. Aqui há uma mudança nos valores sociais, os quais percebem a natureza como algo magnífico que deve ser preservado e contemplado, ou como um lugar que suscita incertezas se completamente devastada. Esta corrente se alinha com a perspectiva denominada por Diegues (2000) de conservacionismo do Norte e que teve forte influência de John Muir. Muitos biólogos defendem esta corrente e a propagam do Norte para o Sul, com apoio de instituições como International Union for the Conservation os Nature (IUCN), o Worldwide Fund of Nature (WWF) e Nature Conservancy (ALIER, 2007).

A segunda corrente para a qual os movimentos ecologistas se encaminharam foi o evangelho da ecoeficiência, que leva a discussão para o controle do crescimento econômico. "Sua atenção está direcionada para os impactos ambientais ou riscos à saúde decorrentes das atividades industriais, da urbanização e também da agricultura moderna" (ALIER, 
2007, p. 26). É através da influência desta corrente que a pauta do desenvolvimento econômico sustentável se firma como um dos meios de aliar ganhos econômicos com ganhos ecológicos, através de modernização tecnológica e manejo consciente dos recursos naturais. Para Alier (2007), a base científica desta corrente é a economia ecológica e a crença na ecoeficiência (inspirado, entre outros, nos ideais de Gifford Pinchot) e nas respostas do mercado com a modernização ecológica (Mol \& Spaargaren, 1993).

Por fim, o ecologismo dos pobres desafia as duas correntes anteriores convocando-as para um debate mais global, profundo e com vistas a incluir a questão social que envolve o debate ambiental. O que acontece é que a dominação historicamente existente do Norte para o Sul vai refletir também nas questões ambientais, através da lógica de exploração do mercado econômico. Os impactos gerados por essa exploração aumentam as externalidades nos países do Sul e nem as políticas públicas de criação de parques, ou as inovações tecnológicas com vistas a uma ecoeficiência resolvem o problema. Segundo Alier,

[...] o eixo principal desta terceira corrente não é uma reverência sagrada à natureza, mas, antes, um interesse material pelo meio ambiente como fonte de condição para a subsistência; não em razão de uma preocupação relacionada com os direitos das demais espécies e das futuras gerações de humanos, mas, sim, pelos humanos pobres de hoje. [...] Sua ética nasce de uma demanda por justiça social contemporânea entre os humanos (2007, p. 34).

Circunstâncias que envolvem a biopirataria (uso dos conhecimentos tradicionais sobre plantas, sementes e manejo que são explorados sem dar os devidos créditos, nem repartição de benefícios), o racismo ambiental (quando as externalidades do mercado econômico impactam segmentos subalternos, principalmente na desproporcional exposição a agentes poluentes e na contaminação de áreas ocupadas por comunidades negras e indígenas - como a construção de plantas industriais, implantação de lixões etc.) e outras formas de injustiças ambientais, têm feito o movimento crescer entre os países com grande índice de pobreza. Além da poluição, outras formas de atuação podem impedir a continuidade da atividade base de algumas comunidades, como no caso de barcos pesqueiros de alta tecnologia que tiram a possibilidade de sobrevivência de comunidades ribeirinhas, que têm sua economia baseada na pesca artesanal; disputas territoriais entre grandes empresas de monocultura que cercam ou expulsam comunidades tradicionais de base agrícola; mineradoras que contaminam a terra e a água; instalação de hidrelétricas em locais que removem comunidades e tantos outros exemplos. Essa corrente recebe apoio de sociólogos, economistas ecologistas que atuam na seara ambiental (ALIER, 2007).

O ecologismo dos pobres tem recebido nomenclaturas diversas, importando como chave-mestra a relação com a justiça social das minorias, que como bem afirma Alier (2007), são maiorias. Os conflitos desta natureza, que tem fundamento na relação entre desigualdade social e crescimento econômico, podem ser percebidos em escalas locais, regionais, nacionais e globais. Ocorre que tais conflitos muitas vezes não são visibilizados enquanto conflitos ambientais, tampouco geram discursos ambientalistas por parte daqueles que são desfavorecidos nesta relação. No entanto, é importante perceber a amplitude da discussão ambiental e que a mesma não perpassa somente pelas duas correntes anteriores - que defende a natureza silvestre, ou que defende o manejo sustentável pela economia. 
Estar atento à diversidade de discursos dentro do ambientalismo é também perceber o ponto de comunhão - quando todos se unem contra o lobby antiecologista. "No Sul, os ambientalistas são em muitas ocasiões atacados pelos empresários e pelo governo [...], considerados serviçais de estrangeiros cujo objetivo é estancar o desenvolvimento econômico" (ALIER, 2007, p. 39). Então compreender as ramificações e perceber que elas podem se servir umas às outras, nas partes que lhes convém, é também uma potencialidade contra-hegemônica nesta disputa entre desiguais.

\section{As faces do desenvolvimento sustentável - UM CONCEIto em disputa frente AO DISCURSO APAZIGUADOR DOMINANTE}

Após a Conferência de Estocolmo, em 1972, que se tornou mundialmente referência para a construção de políticas ambientais, seguiram-se outros eventos de igual ou maior tamanho com o intuito de dar continuidade às discussões iniciadas naquela data. Muito do que motivou a realização desta conferência foi a ocorrência de desastres ambientais de grandes proporções, ocorridos entre as décadas de 60 e 70, resultantes do modelo de produção e do quadro de industrialização que o mercado mundial optou por seguir. Isso pode ser percebido no Princípio 4 da Declaração de Estocolmo sobre o Meio Ambiente Humano, o qual afirma que:

\footnotetext{
O homem tem a responsabilidade especial de preservar e administrar judiciosamente o patrimônio representado pela flora e fauna silvestres, bem assim o seu "habitat", que se encontram atualmente em grave perigo por uma combinação de fatores adversos. Em conseqüência, ao planificar o desenvolvimento econômico, deve ser atribuída importância à conservação da natureza, incluídas a flora e a fauna silvestres (1972).
}

Além de ampliar a discussão ambiental, incluindo no debate mundial o questionamento sobre os modos de produção, a conferência trouxe à tona o debate sobre a solidariedade inter-geracional presente nos Princípios 1 e 2, que falam da obrigação de proteger e melhorar o meio ambiente para as presentes e futuras gerações, além de preservar os elementos (ar, água, solo, fauna e flora) em benefício das gerações atuais e futuras. Deu-se início, assim, a "um impulso e uma adesão de diversas Organizações Internacionais e de diversos Estados à temática ambiental, criando para tal diversos programas de acção, bem como legislação específica para o efeito" (GASPAR, 2005, p. 16).

Em 1984, foi criada a Comissão Mundial sobre Meio Ambiente e Desenvolvimento da ONU, com intuito de medir tanto o avanço da degradação ambiental, quanto o progresso nas políticas públicas em prol do meio ambiente. Como resultado desta ação, em 1987, foi apresentado o Relatório de Bruntland, mais conhecido como Nosso Futuro Comum. Neste documento é apontado o abismo que existe entre os países e como essa diferença é piorada pelas dívidas externas que assolam os países de Terceiro Mundo. Parte-se, então, para a propositura de uma política de consenso que amenize a diferença existente entre os países e possibilite uma estratégia sustentável para o desenvolvimento e a sobrevivência do homem frente aos prejuízos sofridos pelo meio ambiente nestes processos (LEFF, 2001). 
É no Relatório de Bruntland que o termo desenvolvimento sustentável se populariza e se internacionaliza como uma proposta de desenvolvimento que "atenda as necessidades do presente sem comprometer a capacidade de as gerações futuras atenderem às suas" (BRUNTLAND, 1988, p. 9). Ainda sobre o tema, no relatório é pontuada a importância da adesão principalmente dos países ricos, para que estes "adotem estilos de vida compatíveis com os recursos ecológicos do planeta" e que o resto do mundo compreenda que "o rápido crescimento populacional pode intensificar a pressão sobre os recursos e retardar qualquer elevação dos padrões de vida" (BRUNTLAND, 1988, p. 10). Além disso, afirma que

[...] o desenvolvimento sustentável não é um estado permanente de harmonia, mas um processo de mudança no qual a exploração de recursos, a orientação dos investimentos, os rumos do desenvolvimento tecnológico e a mudança institucional estão de acordo com as necessidades atuais e futuras. [...] Assim, em última análise, o desenvolvimento sustentável depende do empenho político (BRUNTLAND, 1988, p. 10).

Com base nesses escritos, infere-se que a proposta da sustentabilidade se relaciona com uma revisão do crescimento econômico-populacional para que a vida na Terra seja viável, principalmente pela continuidade de obtenção e uso de recursos naturais. Neste caso, esta seria uma proposta de viabilidade da sustentabilidade do processo econômico. Com base nisto, a ONU convoca todos os chefes de Estado para a Conferência das Nações Unidas sobre o Meio Ambiente e Desenvolvimento, realizada em 1992, no Rio de Janeiro (Brasil) - conhecida também com a Rio 92, ou Eco 92. Na ocasião, foi produzida a Agenda 21, com a proposta de um programa global com base nos princípios da sustentabilidade, além da indicação para que cada país formulasse a sua agenda nacional (LEFF, 2001).

A temática do desenvolvimento sustentável foi, ao longo dos anos, caminhando para uma ideia de confluência entre ambientalismo e desenvolvimento, propondo a 'conciliação entre os "interesses" econômicos, ecológicos e sociais', e sugerindo que a solução dos conflitos pode ocorrer através da " gestão" do diálogo entre os atores, com a finalidade de se alcançar "consenso"' (ZHOURI, LASCHEFSKI e PEREIRA, 2005, p. 12). Existe um perigo eminente nesta compreensão, pois tal perspectiva gerencial se traduz, muitas vezes, numa falsa noção de resolução de conflito com a participação da sociedade, sendo que esta "participação" é reduzida à simples oitivas dos atores, enquanto que "os conflitos ambientais extrapolam as tentativas de resolução técnica e gerencial propostas pela concepção hegemônica de desenvolvimento sustentável" (ZHOURI, LASCHEFSKI e PEREIRA, 2005, p. 12).

O movimento dos novos ecologismos, que destacou a contradição do modo de produção capitalista, ressaltando a alienação entre a sociedade industrial e a natureza, sujeito e mundo, foi prontamente taxado como romântico e de oposição ao progresso pelos anti-ecologistas. Assim como este movimento, outros foram despolitizados diante das forças hegemônicas da sociedade, "que reconheciam e institucionalizavam aqueles temas ambientais que não colocavam em cheque as instituições da sociedade vigente" (ZHOURI, LASCHEFSKI e PEREIRA, 2005, p. 13). Ou seja, somente os movimentos ambientais que não propunham mudanças nas estruturas conseguiam espaços de fala e é por isso que o desenvolvimento sustentável foi tão bem aceito - por estabelecer um diálogo apaziguador entre ambientalistas e a sociedade industrial, entre meio ambiente e crescimento econômico. 
Acontece que o movimento em defesa do desenvolvimento sustentável, que buscou a interseção na temática ambiental, contribuiu em parte para a generalização da causa e a desqualificação dos movimentos ecologistas que se recusaram a dialogar com esta perspectiva. Além disso, a defesa do meio ambiente pelo viés do desenvolvimento sustentável passou a ser patrimônio comum de todos (campo econômico, político, social etc.). O que se viu nos anos seguintes à década de 1980 foi uma disseminação geral das políticas ambientais, partidos verdes, leis ambientais, mas também uma constante e progressiva piora nos desastres ecológicos, nos conflitos ambientais e na degradação do meio ambiente. Com um destaque a se fazer: as injustiças ambientais continuaram a se concentrar nos espaços das minorias sociais, que não têm lugar de fala, tampouco visibilidade social.

O discurso da ecoeficiência do desenvolvimento sustentável na seara ambiental, quando ignora as questões histórico-sociais, não basta para resolver os conflitos socioambientais.

Pensar a sustentabilidade em uma sociedade tão diversa e desigual como a brasileira requer, além de uma revolução da eficiência e da suficiência, equacioná-la impreterivelmente à diversidade cultural, à democratização do acesso aos recursos naturais e à distribuição dos riscos da produção industrial (ZHOURI, LASCHEFSKI e PEREIRA, 2005, p. 18).

Em consonância com o pensamento de Zhouri, Henrique Leff afirma que “a degradação ambiental é produto de um paradigma societário globalizador e homogeneizante que negou o poder do heterogêneo e o valor da diversidade" (LEFF, 2001, p. 405). Segundo Leff (2001), apesar dessa busca global pelo consenso sobre o futuro mundial comum, o discurso da sustentabilidade não é e não deve ser homogêneo e, muitas vezes, está cercado por conflitos entre visões opostas, como é o caso dos doutrinadores que pensam numa perspectiva tecnicista e os que pensam socioambientalmente. Os tecnicistas visam conciliar a ideia de desenvolvimento com crescimento econômico, visto que para eles a "mão invisível do mercado", de Adam Smith, seria o modo eficaz de assegurar o equilíbrio ecológico e a igualdade social. Assim, caberia à tecnologia reverter os efeitos da degradação ambiental. Por outro lado, os socioambientalistas discutem sobre a irracionalidade produtiva e consumista do capitalismo e visam construir novos estilos de vida, de produção e de consumo voltados ao respeito ambiental, à democracia, ao igualitarismo, à justiça ambiental e à diversidade.

Eleger a política do desenvolvimento sustentável como um discurso consensual é, portanto, uma escolha arriscada. Em verdade, este é um termo em disputa que, muitas vezes, é usado em privilégio das camadas socioeconômicas dominantes, inseridas no contexto capitalista, na tentativa de uniformizar as demandas e ignorar a diversidade. É necessário pensar a questão ambiental sob uma perspectiva de reforma democrática, conforme pontua Leff:

A problemática ecológica questiona os custos socioambientais derivados de uma racionalidade produtiva fundada no cálculo econômico, na eficácia dos sistemas de controle de previsão, na uniformização dos comportamentos sociais e na eficiência de seus meios tecnológicos. A questão ambiental estabelece assim a necessidade de introduzir reformas democráticas no Estado, de incorporar normas ecológicas ao processo econômico e de criar novas técnicas para controlar os efeitos contami- 
nantes e dissolver as externalidades socioambientais geradas pela lógica do capital (LEFF, 2001, p. 133).

A "racionalidade produtiva fundada no cálculo econômico" e a "uniformização de comportamentos sociais", citados no trecho acima, podem ser associadas à história do capitalismo e do crescimento econômico ocidental, assim como a formação e desenvolvimento das regulamentações ambientais, que foi ampliada diante das crises ecológicas ao final do séc. XX. Essa conjuntura contribui para uma contraposição entre os campos da economia e da proteção ao meio ambiente - que se reflete numa aparente incompatibilidade entre alguns ramos do Direito e o Direito Ambiental, por exemplo. Dentro do paradigma da ciência moderna, é importante frisar a busca pelos pensamentos universalistas e globalizantes, que dificultaram, e ainda dificultam, as possibilidades de aliar crescimento econômico com estratégias ambientalistas democráticas.

No Brasil, por exemplo, os últimos anos tem sido de investimentos em obras infraestruturais de grande porte, como hidrelétricas, rodovias, ferrovias e hidrovias que integram o PAC (Programa de Aceleração do Crescimento) I e II com sua promessa de "desenvolvimento acelerado e sustentável". No entanto, muitos são os conflitos ambientais que permeiam estes processos, tendo como representantes tanto comunidades tradicionais e indígenas, como representantes de movimentos ambientalistas. Nestes entraves, dois aspectos do Estado se mostram destacadamente em disputa - de um lado a esfera econômica representada pelo Estado empreendedor e do outro a esfera socioambiental representada pelo Estado protetor. De acordo com Zhouri, essa dinâmica conflituosa instaurada com a implementação de uma 'política conservadora de ajuste econômico tem reconduzido meio ambiente e justiça social ao estatuto de "barreiras do desenvolvimento"' (ZHOURI, LASCHEFSKI e PEREIRA, 2005, p. 11).

Isto aponta que existe uma disputa entre campos dentro do próprio Estado e que ambos os lados se apropriam do conceito de desenvolvimento sustentável. O conceito de desenvolvimento sustentável, que apesar de se propor universal e consensual, traz uma concepção hegemônica e dominante que coloca o elemento "natureza" como algo fora do contexto da sociedade e a converte 'em uma simples variável a ser "manejada", administrada e gerida, de modo a não impedir o desenvolvimento' (ZHOURI, LASCHEFSKI e PEREIRA, 2005, p. 15). Pode-se verificar isto na forma como a preservação do meio ambiente vem sendo negociada, a exemplo do que ocorreu na Rio+20, quando os debates buscaram "convencer os mercados (sempre livres, sem qualquer restrições) sobre as oportunidades de lucro em investirem no meio ambiente, calculando custos ambientais e atribuindo valor de mercado à natureza. Ou seja, não há outro modo de nos relacionarmos entre humanos e com a natureza que não seja o mercado" (SANTOS, 2012).

Para Leff (2001), a conjuntura ambiental que abre o novo milênio convida à revisão e à reflexão da produção teórica e filosófica até então sustentada. É uma provocação para a produção de uma nova racionalidade ambiental. "A crise ambiental questiona as premissas ontológicas, epistemológicas e éticas que serviram de base à modernidade, negando as leis-limite e os potenciais da natureza e da cultura [...]" (LEFF, 2001, p. 405). Ao mesmo tempo em que o discurso da sustentabilidade se projeta para o futuro, para uma solidariedade intergeracional, ele denuncia o passado, tudo isso em um fluxo histórico (distante da con- 
cepção de linearidade).

A atualidade torna-se palco da coexistência de tempos diversos onde se apresentam de "tradições congeladas e bloqueadas pelos tempos de dominação e repressão histórica, até o entrelaçamento das diversas racionalidades que constituíram as formas humanas de relação com a natureza" (LEFF, 2001, p. 410). Tal conjuntura denuncia a insustentabilidade da perspectiva dominante do desenvolvimento sustentável, que quer restringir a racionalidade ambiental à economia verde, às dinâmicas do desenvolvimento econômico mundial, à universalização de uma racionalidade que exclui a diversidade.

A sustentabilidade pode tornar-se sustentável, no entanto, como um projeto contra-hegemônico que dê voz à diversidade/heterogeneidade sociocultural, historicamente calada por uma visão homogênea, universalizante, monolítica e unipolar. Como afirma Leff (2001, p. 415), a tentativa de unificar o mundo, "o Deus único, a ideia absoluta, a unidade da ciência e a globalização do mercado" é um projeto falido. Portanto, a disputa que envolve o desenvolvimento sustentável reflete não só a crise da modernidade e da civilização, como também propugna uma transformação da existência humana (LEFF, 2001). E a obtenção disto passa também por uma discussão ética, a fim de recriar sentidos e refazer caminhos dentro de uma nova racionalidade ambiental.

\section{Caminhos para a visibilização do ecologismo dos pobres - É POSSível ir além DO PENSAMENTO TEÓRICO-JURÍDICO HEGEMÔNICO?}

Também no final da década de 70 e início dos anos 80, entra na pauta dos ecologistas os saberes tradicionais sobre o meio ambiente detido por povos e comunidades, que mantiveram a interação homem/natureza de modo a preservar e ainda ampliar a biodiversidade. As comunidades e povos tradicionais ganham destaque mundial quando inseridos na Declaração de Estocolmo, na qual se "reconheceu o papel dos povos indígenas e das comunidades camponesas, sem que fossem enunciadas, contudo, medidas específicas de proteção" (ALONSO, 2005, p. 291). Após 10 anos, como resultado da Eco92, no Rio de Janeiro,

\footnotetext{
A Declaração do Rio sobre Meio Ambiente e Desenvolvimento (Princípio 22) faz uma menção específica acerca da importância que os conhecimentos e práticas tradicionais têm para o ordenamento do meio ambiente e do desenvolvimento. E é por causa desse interesse particular que os Estados devem reconhecer a sua identidade, cultura e interesses (ALONSO, 2005, p. 291).
}

São muitos, depois destes, os documentos nacionais e internacionais que incluíram os saberes tradicionais como fundamentais para o debate socioambiental e para a manutenção da biodiversidade e disseminação de conhecimentos tradicionais. No Brasil, além das normas constitucionais, destaca-se a criação do Decreto 6.040/2007 que institui a política nacional de desenvolvimento sustentável dos povos e comunidades tradicionais. Neste instrumento, define-se povos e comunidades tradicionais como: 
grupos culturalmente diferenciados e que se reconhecem como tais, que possuem formas próprias de organização social, que ocupam e usam territórios e recursos naturais como condição para sua reprodução cultural, social, religiosa, ancestral e econômica, utilizando conhecimentos, inovações e práticas gerados e transmitidos pela tradição (BRASIL, 2007).

Além desta definição, o referido decreto traz a importância do reconhecimento territorial como essencial à reprodução cultural, social e econômica destes grupos. A despeito da importância de se legislar sobre o direito das minorias sociais, cumpre salientar que os problemas não se encerram na conquista destes instrumentos normativos. Segundo Julio Cesar de Sá da Rocha,

Com o surgimento de um sistema legal pluri e multiétnico, o desfaio é como seus operadores devem lidar com a temática dos povos e comunidades tradicionais, as relações de forças específicas e as lutas de concorrência para a afirmação dos direitos dos grupos étnicos (2015, p. 25).

É como se, para fugir da crise social e ecológica, criar leis e instrumentos normativos reconhecendo estas populações seria a solução suficiente. No entanto, o que torna o movimento de visibilização uma tarefa difícil, segundo Margarita Alonso, é justamente sair da lógica homogeneizante da globalização e incluir estas populações no debate considerando a diversidade cultural e a relação integrada destas com a natureza. "O reconhecimento da diversidade cultural implica o reconhecimento de outros modos de vida alternativos, que, muito embora tenham beneficiado a biodiversidade, não esgotam a sua importância nessa função [...]" - o que demonstra que para compreender os saberes tradicionais é preciso transcender a dimensão instrumental na relação homem/natureza (ALONSO, 2005, p. 293).

Além disso, Alonso (2005) afirma que os saberes tradicionais destas comunidades padecem de uma "erosão cultural" causada pelo modo como são vistos pela cultura ocidental, que subvalorizam estes conhecimentos frente à ciência e à tecnologia. Isso se torna evidente pela própria nomenclatura concedida a estas culturas: o termo "tradicional" pode representar uma antinomia ao termo "moderno"; e o moderno, por sua vez, é definido a partir de um referencial hegemônico dos países desenvolvidos. Na tentativa de proteger estes conhecimentos tradicionais, assim como ocorre com o meio ambiente, surge a impossibilidade de uma proteção isolada, pois estes conhecimentos

[...] se reproduzem de forma coletiva, cumulativa, e em resposta a situações e motivos muito diferenciados. São conjuntos complexos que se apóiam na tradição, na observação e na utilização dos processos e recursos biológicos. Correspondem a concepções integrais de relação sociedade/natureza e exprimem-se e sistematizam-se através de mitos, rituais, narrações de caráter oral e práticas relacionadas com sistemas de ordem ambiental e de saúde, com instituições e regulamentos estabelecidos para lhes aceder e para os aplicar, aprender e transmitir (ALONSO, 2005, p. 296). 
Ou seja, este não é um saber empírico ‘sobre o qual se possa erigir outro tipo "superior" de conhecimento a ser protegido, mas sim de um conhecimento que tem valor em si mesmo e que se protege com mecanismos próprios', pela própria estrutura e método milenar (ALONSO, 2005, p. 298). A lógica não é a mesma da ciência moderna - sistematizar/ separar/dissecar para dominar e conhecer. São saberes coletivos, que se exprimem em um dado território e através deste território. Por isso a relação com o território é tão importante, sendo os direitos intelectuais um prolongamento dos direitos territoriais, conforme explica a Alonso (2005).

Outra autora que vem afirmar a importância do território para as comunidades tradicionais, na relação homem/terra, é Edna Castro (1997). Ela afirma que a produção de saberes de inúmeros grupos tradicionais está diretamente relacionada ao uso e posse comum da terra e que é no território que a manutenção, reprodução e a coesão da identidade se perfazem. A sociedade ocidental, pelo contrário, construiu uma relação diferente com seu entorno. Esta relação foi de dominação, coisificação, transformação em bem, de modo a privatizar e aproveitar os recursos, muitas vezes, indiscriminadamente (CASTRO, 1997).

Diante da enorme diversidade que os povos tradicionais apresentam, pode-se colocar o campo da atividade produtiva como um lugar que promove certa coerência entre elas. Nos modos de produção está também a sociabilidade, a sacralidade, a relação com a natureza, o conhecimento prático, cotidiano, acumulado e passado por gerações (CASTRO, 1997). A relação com o entorno, o vasto conhecimento adquirido sobre o meio ambiente complexo, "realiza-se graças aos saberes acumulados sobre o território e às diferentes formas pelas quais o trabalho é realizado" (CASTRO, 1997, p. 169). Reconhecer essas práticas e integrá-las como possíveis na sociedade contemporânea ainda é um grande desafio. O paradigma dominante da ciência moderna subalterniza a oralidade e o conhecimento prático passado por gerações; o campo econômico, por sua vez, desqualifica o trabalho que não se realiza segundo o critério da produtividade.

Trata-se de dois sistemas onde o técnico-econômico funciona sob normas diferentes e que dá resultados e efeitos também diferentes sobre o meio ambiente. Respaldando-se em representações que reforçaram, no passado, os preconceitos, nossa sociedade moderna vê aquelas práticas tradicionais de trabalho como improdutivas (CASTRO, 1997, p. 170).

4.1 A herança do pensamento teórico-Científico moderno e a SUbSUnÇÃo do local AO GLOBAL

O paradigma do pensamento moderno impôs uma via de mão única para o conhecimento, deslegitimando outras formas de produção de saber. Apesar da quantidade crescente de pesquisas e debates que buscam o reconhecimento dos saberes tradicionais, ainda existem grandes barreiras sedimentadas pela história do pensamento moderno a serem transpostas. Além desta, a barreira do capitalismo, que ao reduzir tudo a um valor econômico, descarta esses saberes que não podem ser vendidos. Tendo na base do processo de produção o uso comum da terra, essas comunidades contestam a hegemonia do indivíduo, da propriedade privada e da relação de separação entre o homem e a natureza. 
As críticas ao pensamento moderno e hegemônico já motivaram a emergência de diversas outras linhas de pensamento. Mas o que faz ainda hoje esse pensamento reverberar? Segundo Boaventura de Sousa Santos, a ciência moderna engendrou um protagonismo excepcional ao se propor "não apenas compreender o mundo ou explicá-lo, mas também transformá-lo. Contudo, paradoxalmente, para maximizar a sua capacidade de transformar o mundo, pretendeu-se imune às transformações do mundo" (2006, p. 128). Assim, o debate dicotômico entre sujeito/objeto, homem/natureza, objetividade/subjetividade tanto influenciou uma série de debates concordantes, como discordantes. Certo é que o conhecimento construído de forma a privilegiar determinada parcela da sociedade rende benefícios socioeconômicos, políticos e culturais a estes, enquanto desprivilegia a outra parcela da sociedade (SANTOS, 2006).

De forma paralela, é indispensável apresentar outro movimento entre intelectuais, incialmente, indianos e, posteriormente, latino-americanos que afirmam a concepção de um "giro de paradigma", defendendo a "opção decolonial" - epistêmica, teórica e política para compreender e atuar no mundo. (GROSFOGUEL, 2008, p.116). "Giro decolonial" é um termo que significa o movimento de resistência à lógica da modernidade/colonialidade. O Grupo compartilha noções, raciocínios e conceitos que lhe conferem identidade e vocabulário próprio, contribuindo para a renovação analítica e utópica das ciências sociais latino-americanas do século XXI, propondo uma fratura entre a pós-modernidade e a póscolonialidade. As origens da ideia de decolonialidade estavam contidas em apontamentos de Quijano e Dussel. Para Luciana Ballestrin (2013, p.110):

Dentre as contribuições consistentes do grupo, estão as tentativas de marcar: (a) a narrativa original que resgata e insere a América Latina como o continente fundacional do colonialismo, e, portanto, da modernidade; (b) a importância da América Latina como primeiro laboratório de teste para o racismo a serviço do colonialismo; (c) o reconhecimento da diferença colonial, uma diferença mais difícil de identificação empírica na atualidade, mas que fundamenta algumas origens de outras diferenças; (d) a verificação da estrutura opressora do tripé colonialidade do poder, saber e ser como forma de denunciar e atualizar a continuidade da colonização e do imperialismo, mesmo findados os marcos históricos de ambos os processos; (e) a perspectiva decolonial, que fornece novos horizontes utópicos e radicais para o pensamento da libertação humana, em diálogo com a produção de conhecimento". (BALLESTRIN, 2013, p.110)

De outra forma, o discurso consensual, com vistas a atender as necessidades de uma pequena parcela da sociedade, fez insurgir diferenciações dentro dos movimentos sociais, antes colocados em uma mesma categoria. Isso aconteceu, por exemplo, no movimento feminista, que demonstrou a impossibilidade de um discurso uníssono e emergiu em frentes variadas na luta pela igualdade material, formando diversos movimentos feministas. Assim também ocorre com a temática ambiental, que demonstra "a inviabilidade das tentativas que procuram forjar essa mesma unidade para a constituição de um movimento ambientalista no singular" (ZHOURI e OLIVEIRA, 2010, p. 440). Maria da Glória Gohn (2011) explica essa diversidade dos movimentos sociais a partir da realidade que vivenciam, pois estas forças atuam diante das situações adversas que surgem no cotidiano. Estas reflexões demandam uma revisão do modelo globocêntrico, onde é embutida uma hierarquia do global para o local também nas discussões que permeiam os movimentos sociais. 
Os assuntos que ganham a dimensão global e se situam como centrais, como o caso do aquecimento global e das alterações climáticas, acabam por tornar o lugar sem conteúdo. Assim, o que ocorre no local fica subsumido ao global (ZHOURI; OLIVEIRA, 2010). "Diante do exposto, entendemos a necessidade de se colocar o desafio, a um só tempo intelectual e político, de resgatar os processos locais, incorporando novos marcos e categorias de análise aos processos globais" (ZHOURI; OLIVEIRA, 2010, p. 444).

\begin{abstract}
Na sociedade, os sujeitos sociais apresentam-se como portadores de relações e interações diferenciadas com o meio ambiente, considerado como uma construção ao mesmo tempo simbólica, social e material. Além de diversos, os sujeitos se localizam desigualmente na sociedade. [...] Essas assimetrias revelam a hegemonia de determinadas categorias do pensamento que pretendem construir o debate ambiental como global, universal e consensual, obscurecendo as relações de poder que, de fato, existem e promovem o deslocamento da política para a economia, do debate sobre direitos para o debate sobre interesses (ZHOURI; OLIVEIRA, 2010, p. 444).
\end{abstract}

As comunidades tradicionais quando envolvidas em conflitos territoriais têm, portanto, lutado para provar o valor do lugar, do meio ambiente, da territorialidade contra a coisificação do lugar presente nos processos capitalistas desenvolvimentistas. E, segundo Zhouri e Oliveira (2010), a afirmação identitária, a resistência à subjugação e desterritorialização demonstram que estes grupos sociais estão se reapropriando da possibilidade de decidir o futuro da própria vida. A crise do meio ambiente, portanto, deve ser analisada juntamente a essa realidade e não exclusivamente por um discurso hegemônico, a exemplo da compreensão dominante de desenvolvimento sustentável, que nega a diversidade frente à pretensão de universalizar e produzir consensos, excluindo o local em nome do global.

4.2 ENTRe dois Judiciários e dois Estados: as brechas PARA A Visibilização da COMPLEXIDADE SOCIOAMBEINTAL

Não se pode perder de vista que a política desenvolvimentista brasileira tem protagonizado diversos conflitos envolvendo territórios tradicionais e a expansão do agronegócio e monocultura, a construção de hidrelétricas, a realização de projetos de construção de vias e ferrovias etc. Muitos desses conflitos se configuram de modo a surpreender as comunidades, que nem sempre estão organizadas formalmente e politicamente para o embate. Como são sujeitos historicamente invisibilizados e subalternizados, é comum que estes grupos não sejam portadores dos títulos de propriedade, o que os coloca em situação de informalidade. A posse, apesar de protegida pelo Direito brasileiro, tem de lidar com a hierarquia de outro direito mais protegido pela esfera estatal, que é o de propriedade. Isto se torna ainda mais relevante no protagonismo exercido pelo judiciário diante das causas sociais, em parte do séc. XX, quando se demonstrou a inclinação conservadora de muitos tribunais diante da agenda política dos atores progressistas (SANTOS, 2008).

Na década de 30, por exemplo, a corte suprema dos EUA impediu algumas reformas propostas por Roosevelt ao invocar "concepções de direito civil e de propriedade estritamente individualista que não permitiam fazer avançar as reformas" (SANTOS, 2008, p. 11). Na atualidade, a política de desenvolvimento neoliberal agregou ao sistema de leis um perfil voltado para a eficiência e celeridade do comércio, segurança jurídica nas relações 
contratuais que possibilite e atraia investimentos e lucro. A proteção do direito de propriedade, dentro desse contexto, é de fundamental importância. No entanto, o neoliberalismo deixa, há algum tempo, as marcas de sua insuficiência e ineficiência acerca do crescimento, da igualdade social, da degradação ambiental.

Segundo Santos (2008), esta conjuntura possibilita a existência de dois grandes campos no judiciário. O primeiro confirma a linha anteriormente falada, apresentando-se como campo hegemônico, para que se "permita a previsibilidade dos negócios, dê segurança jurídica e garanta a salvaguarda dos direitos de propriedade" (SANTOS, 2008, p. 20). De acordo com a análise de Santos (2008), é com base no viés desse primeiro campo que ocorrem a maioria das reformas do judiciário com vistas a se tornar mais célere. O segundo campo ocupa o lugar da contra-hegemonia, sendo ocupado por organizações da sociedade civil das mais diversas, que usam os instrumentos do campo do Direito (sistema legal e operativo) para reivindicar o cumprimento de direitos - com vistas à exclusão, precarização do trabalho, degradação ambiental, desigualdade social etc. (SANTOS, 2008).

A inserção do Direito nesse debate é imprescindível justamente por ser uma das principais vias de acesso à cidadania.

\begin{abstract}
O tema dos direitos é fundamental, porque dá universalidade às questões sociais, aos problemas econômicos e às políticas públicas, atribuindo-lhes caráter emancipatório. É a partir dos direitos que fazemos o resgate da cultura de um povo e de uma nação, especialmente em tempos neoliberais que destroem ou massificam as culturas locais, regionais ou nacionais. [...] A óptica dos direitos possibilita-nos a construção de uma agenda de investigação que gera sinergia, não compaixão, que resulta em políticas emancipadoras, não compensatórias. Fora da óptica da universalidade dos direitos, caímos nas políticas focalizadas, meras justificativas para políticas que promovem uma modernização conservadora (GOHN, 2011, p. 347).
\end{abstract}

Muitas das terras habitadas por populações tradicionais no Brasil encontram-se em terras da União ou do estado e no processo de requisição da titulação das terras (direito concedido pela CF/88) esbarram nos projetos de desenvolvimento, ou energético, ou viário, do governo (além dos casos de sobreposição com terras privadas). Isto resulta numa disputa entre setores do Estado, já que ao mesmo tempo em que existem os projetos de desenvolvimento, existe também um comprometimento em escala nacional de promover políticas de reparação em diversas frentes junto às populações tradicionais.

$\mathrm{Na}$ Bahia, por exemplo, apesar das 734 comunidades quilombolas já organizadas e certificadas pela Fundação Palmares (http://www.palmares.gov.br/wp-content/ uploads/2017/05/quadro-geral-15-05-2017.pdf), apenas seis conseguiram chegar ao fim do longo e burocrático processo e obter a titulação de suas terras. E essas que obtiveram o título não passaram por isso sem antes enfrentaram situação de conflito territorial, a maioria, decorrentes de terras griladas. Apesar do baixo número de títulos obtidos, tamanha a dificuldade que o processo impõe, o número de comunidades quilombolas reconhecidas na Bahia demonstra a crescente participação destas populações na busca pela efetivação de seus direitos coletivos. 
Para Almeida (2006), a emergência de novos movimentos sociais que incorporam à sua pauta fatores étnicos, ecológicos e de autodefinição coletiva está intimamente relacionada a esses processos de territorialização que visam proteger as terras tradicionalmente ocupadas e geridas por modelos particulares de uso comum, historicamente mantidos sob o signo da invisibilidade social (ZHOURI; OLIVEIRA, 2010, p. 447).

Além desse fator, Santos (2006) também acredita que a abertura para perspectivas interculturais contribuiu para a visibilização de saberes alternativos à lógica dominante e ocultados pelo paradigma da ciência moderna.

\begin{abstract}
A abertura a uma pluralidade de modos de conhecimento e a novas formas de relacionamento entre estes e a ciência tem sido conduzida, com resultados profícuos, especialmente nas áreas mais periféricas do sistema mundial moderno, onde o encontro entre saberes hegemônicos e não hegemônicos é mais desigual e violento. Não por acaso, é nessas áreas que os saberes não hegemônicos e os seus titulares mais necessidade têm de fundar a resistência em processos de auto-conhecimento que mobilizam o contexto social, cultural e histórico mais amplo que explica a desigualdade, ao mesmo tempo que gera energias de resistência contra ela (SANTOS, 2006, p. 141).
\end{abstract}

É diante da hegemonia do discurso do desenvolvimento econômico sustentável do Estado e do mercado, ou diante do conservacionismo presente na gestão de alguns parques, que o local luta para se sobrepor ao discurso do global. A tentativa de destituir o lugar de qualquer valor compõe uma das contraposições que insurgem das transformações das hierarquias do conhecimento - global/local; moderno/tradicional; desenvolvido/subdesenvolvido; sujeito/objeto. O meio ambiente, o território, o coletivo, todos estes componentes que se interligam e possuem relação de interdependência acabam sendo desvalorizados diante da necessidade apresentada através de um discurso globalizante. Com o esvaziamento de valor em si, tudo se torna um valor monetário e toda a complexa relação do lugar é transformada em "indenização e remanejamento", como afirma Zhouri e Oliveira (2010, p. 456). Mas é nas brechas deixadas pelas disputas que ocorrem dentro do próprio Estado e do próprio aparato estatal judiciário que emergem demandas do movimento socioambiental das populações tradicionais - estampando estas contradições de modo a não ser mais possível silenciá-las.

Convém ressaltar que segmentos e populações tradicionais têm acessado os instrumentos regionais de resolução de conflitos na Comissão e a Corte Interamericana de Direitos Humanos. A comissão é órgão autônomo da Organização dos Estados Americanos (OEA) encarregado da promoção e proteção dos direitos humanos no continente americano, juntamente com a Corte Interamericana de Direitos Humanos, instalada em 1979, que é uma instituição do Sistema Interamericano de proteção dos direitos humanos (SIDH). 


\subsection{OS AMBientalismos INSURgenteS}

Em contraponto à lógica hegemônica, da metade do século XX em diante, novas perspectivas científicas anti-reducionistas se espalharam como forma de estabelecer uma contra-hegemonia ao pensamento dominante. "Em vez do simples, o complexo: [...] em vez da separação entre sujeito e objeto, o objeto que é sujeito; em vez da separação entre o pensar e o agir, a interatividade entre ambos no processo de investigação" (SANTOS, 2006, p. 131). Conceber a diversidade epistemológica do mundo passa pela renúncia, revisão e reformulação da ideia de uma epistemologia única (SANTOS, 2006). Ocorre que a epistemologia positivista dominante descredibiliza qualquer alternativa epistemológica, pois ocupa o lugar de único conhecimento válido e rigoroso, uma vez que a "modernidade ocidental, enquanto paradigma sociocultural, reduziu as possibilidades de emancipação às compatíveis com o capitalismo" (SANTOS, 2006, p. 143).

Para superar esse embate no qual as alternativas são sempre desqualificadas e desconsideradas pelo paradigma da ciência moderna, Santos propõe a via da ecologia de saberes. Considerando ecologia como a

“[...]pluralidade de saberes heterogêneos, da autonomia de cada um deles e da articulação sistêmica, dinâmica e horizontal entre eles. A ecologia de saberes assenta na independência complexa entre os diferentes saberes que constituem o sistema aberto do conhecimento em processo constante da criação e renovação. O conhecimento é interconhecimento, é reconhecimento, é autoconhecimento (SANTOS, 2006, p. 145)".

A proposta não visa excluir ou destituir de valor o conhecimento científico. Mas desperta para a possibilidade de usar este conhecimento de forma contra-hegemônica, assim como é possível usar o Direito de forma insurgente. Dentro da ecologia de saberes, o princípio da precaução é colocado por Santos (2006) como forma de ponderação no uso dos conhecimentos, optando sempre que possível pelas formas que mantenham os grupos sociais frente ao contexto de participação e atuação (SANTOS, 2006).

Inclusive, entre os anos 1990 e a primeira década do séc. XXI, a reorganização dos movimentos sociais vem possibilitando a ampliação do protagonismo destes na fase democrática do Brasil. Isto devido, em parte, pelo processo de institucionalização das organizações populares (através de Fóruns, ONGs, associações) e da institucionalização das formas de participação popular criado pelo próprio Estado, como os conselhos. Estes instrumentos, ao passo que podem camuflar processos de dominação possibilitando um "falso" lugar de fala, também guardam potencialidades de uma via emancipatória que tem no Direito contra-hegemônico o seu maior cúmplice.

\section{Ordep SERra e a CONCEPÇÃo EMANCIPATÓRIA EM DEFENDER DiREITOS DAS COMUNidAdeS}

A concepção emancipatória de caráter pós-colonial e decolonial tem no antropólogo Ordep Serra uma das mais contundentes vozes em defesa das comunidades, respeito às culturas e de uma contra-hegemonia ao pensamento dominante. Serra é responsável por uma 
vasta obra acadêmica e literária reconhecida nacional e internacionalmente, bem como, um ativista na garantia de direitos, exercendo papel central em defesa das comunidades tradicionais. Por sua vez, um dos casos mais destacados da atuação do pesquisador foi o tombamento pelo IPHAN do Ilê Axé Iyá Nassô Oká, Terreiro da Casa Branca do Engenho Velho e elaboração de laudo antropológico que teve papel central na sua efetivação, que contribuiu para fazer da Casa Branca o primeiro monumento negro tombado no Brasil. Ordep elaborou laudos antropológicos do Terreiro do Bogum, Zoogodô Bogum Malê Rundó, Terreiro do Bate Folha e Terreiro do Gantois, Ilê Axé Iá Omin Iamassê.

Para Ordep Serra um terreiro vem a ser um centro religioso e uma forma tradicional de assentamento:

\begin{abstract}
“[...]que sedia um grupo eclesial estruturado segundo as normas de um rito afro-brasileiro. A palavra é dicionarizada, tendo este sentido particular reconhecido e seu emprego verifica-se comum na vasta etnografia especializada (cf. Lépine, 1982: 68 , s. v., Becker 1995, s.v.). O designativo candomblé, termo de origem quimbundo por cujo emprego se identifica, hoje, uma modalidade de culto afro-brasileiro, pode também aplicar-se a um centro onde esse culto é praticado: v.g. candomblé do Engenho Velho, candomblé do Gantois. (cf. Cacciatore, 1977; Lépine, op. cit., s.v.; Becker, 1995, p. 374, s.v.; Salvador, 1982). A palavra roça é ainda empregada, embora cada vez menos, para indicar o espaço físico dos terreiros de candomblé; algumas pessoas ainda falam em Roça do Engenho Velho referindo-se ao Candomblé da Casa Branca. Em casas de culto do rito ketu, na Bahia, a expressão ebé (do ioruba egbé, cf. Abraham, 1958 s.v.) se usa para assinalar o tipo de grupo eclesial que se dedica a essa liturgia; o termo axé também pode ser empregado nesta acepção. O estabelecimento que lhe corresponde - o terreiro propriamente dito, o espaço consagrado que sedia o rito - neste meio chama-se ainda, como se viu, ilê axé, ou ilê orixá".
\end{abstract}

Numa perspectiva crítica, Ordep Serra constitui proposta concreta de "ambientalismo insurgente" com vocalização dos interesses das comunidades, incorporando na academia concepções emancipatórias. Efetivamente, explicita de forma categórica a relação entre raça/ cor, etnia, desigualdade e conflito no Brasil, apontando graves ocorrências de intolerância religiosa. Em verdade, Serra faz um giro decolonial na prática, significando o movimento de resistência à lógica da modernidade/colonialidade com valorização do candomblé com seu "ambientalismo tradicional de ancestralidade negra" pois sem folhas não há orixá (Kó si ewé, kó sí Òrìsà).

\section{Considerações Finais}

A revolução proporcionada pelo pensamento moderno contribuiu decisivamente para o desenho da política econômica neoliberal no sistema-mundo atual e, por sua vez, para a consolidação das desigualdades e abismos sociais. O pensamento moderno constrói uma racionalidade ética completamente voltada para o homem - mas não o homem compreendido em sua diversidade, e sim o homem que ocupa o lugar de dominação. Do lugar central, a este homem é dada a possibilidade de controlar, dominar, sobrepor-se. A faculdade de raciocinar desloca a relação do homem com o seu entorno para a relação su- 
jeito-objeto. Esta separação, por sua vez, contribui para o desenvolvimento da razão técnico-instrumental, estabelecendo o lugar da eficiência, dos resultados, que combina com o desenvolvimento econômico capitalista e neoliberal.

Discutir a crise ambiental sem passar pela construção do pensamento moderno é trabalhar em cima de políticas paliativas. A importância deste debate está, justamente, em questionar determinados posicionamentos que assumem o lugar de dominação frente a um aparato ideológico que privilegia uma pequena parcela da sociedade, detentora do poder político-econômico. A construção do conhecimento moderno é percorrida por relações de poder que exerce uma força simbólica de dominação sobre aqueles que não perfazem essa relação. Mas como em toda dominação existem os dominados, daí insurgem negociações que muitas vezes tencionam a relação. Surgem também propostas emancipatórias que, ao utilizar as forças do próprio sistema, como o Direito, trazem para a pauta as suas demandas e perspectivas contra-hegemônicas de caráter pós-colonial e decolonial.

No presente artigo, ao trazer a perspectiva das populações tradicionais, buscou-se demonstrar a importância do diálogo entre saberes e de como a construção do saber ambiental enriquece ao ser diverso e inclusivo. Os inúmeros conflitos territoriais que envolvem essas comunidades por todo o Brasil são, na maioria das vezes, perpassados por compreensões limitadas, dominantes e excludentes. Por isso, ainda se faz importante identificar e situar o pensamento hegemônico, com vistas a dar voz ao pensamento contra-hegemônico e à participação dos atores sociais que são subalternizados por este sistema.

Os movimentos sociais têm usado, muitas vezes, a via jurídica, inclusive acessado os instrumentos regionais, como a Comissão e a Corte Interamericana de Direitos Humanos para reclamar direitos. Por isso, não se pode descartar a importância de uma Constituição que garanta direitos humanos e direitos ambientais de forma igualitária, sem excluir toda a diversidade presente na população brasileira. Promover esta discussão é também uma oportunidade de recriar sentidos e refazer caminhos a fim de construir uma nova racionalidade ambiental. Por fim, numa perspectiva contra-hegemônica de caráter emancipatório pontuou-se a atuação e contribuição da obra do antropólogo Ordep Serra na defesa de direitos das comunidades com valorização do candomblé com seu ambientalismo tradicional de ancestralidade negra.

\section{Notas}

1 Os conceitos de preservação e conservação diferem para alguns autores, sendo o primeiro a garantia da perenidade e inalterabilidade do ecossistema, mantendo-o intocado na medida do possível, e o segundo a busca por incluir a proteção do ecossistema integrado com a presença humana (NOGUEIRA; SIQUEIRA, 2004). No entanto, Diegues (2000), ao usar os termos "conservacionista", ou "conservacionismo", atrela estes termos a um movimento que, tecnicamente, está conectado ao conceito de preservação.

2 A expressão "populações tradicionais" é empregada propositalmente pela abrangência que comporta. No entanto, vale o comentário de que toda categoria que abarca um conceito amplo, enfrenta problemas por isto. Em geral, quando se cria uma categoria que dá nome ao "outro" este ato pode vir carregado de uma perspectiva colonizadora e preconceituosa, mas este mesmo ato também pode permitir que o "outro" se aproprie de tais categorias, transformando-as em bandeira de luta e mobilização - e por isto a abrangência dá maleabilidade ao conceito. Isto aconteceu, por exemplo, com o 
movimento indígena e negro. O termo comunidades tradicionais, ou populações tradicionais, como será usado neste capítulo, vem passando por esse processo de reapropriação e sendo incorporado por movimentos sociais como o de quilombolas, fundo e fecho de pasto, marisqueiras e pescadores, seringueiros, castanheiros, indígenas, entre outros. Importante frisar aqui que o termo será referido a grupos que têm em comum a relação relativamente pouco predatória com o meio em que estão inseridos e passam por situações de luta pela manutenção e/ou recuperação da manutenção, autonomia e controle sobre o território ao qual historicamente estão vinculados (CUNHA; ALMEIDA, 2013). Convém registrar que a Lei da Mata Atlântica (Lei 11.428/2006) adota o conceito de população tradicional como: "população vivendo em estreita relação com o ambiente natural, dependendo de seus recursos naturais para a sua reprodução sociocultural, por meio de atividades de baixo impacto ambiental". Por sua vez, a categoria povos e comunidades tradicionais tem sido utilizada por segmentos acadêmicos (ROCHA \& SERRA, 2015; ROCHA, 2013) e políticas públicas, como: "grupos culturalmente diferenciados e que se reconhecem como tais, que possuem formas próprias de organização social, que ocupam e usam territórios e recursos naturais como condição para sua reprodução cultural, social, religiosa, ancestral e econômica, utilizando conhecimentos, inovações e práticas gerados e transmitidos pela tradição" (Decreto 6.040/2007).

3 Populações tradicionais é aqui entendido de forma extensiva e como toda categoria extensiva enfrenta problemas. A criação de categoria que dá nome ao "outro" é, em geral, carregada de uma perspectiva colonizadora e preconceituosa, mas é também possível que esse "outro" se aproprie de tais categorias transformando-as em bandeira de luta e mobilização, como aconteceu com o movimento indígena e negro, por exemplo. O termo comunidades tradicionais, ou populações tradicionais, como será usado neste artigo, vem passando por esse processo de reapropriação e sendo incorporado por movimentos sociais como o de quilombolas, fundo e fecho de pasto, marisqueiras e pescadores, seringueiros e castanheiros, entre outros. Importante frisar aqui que o termo será referido a grupos que têm em comum a relação pouco predatória com o meio em que estão inseridos, configurando um baixo impacto ambiental, e passam por situações de luta pela manutenção e/ou recuperação da manutenção, autonomia e controle sobre o território ao qual historicamente estão vinculados (CUNHA; ALMEIDA, 2013).

4 A proposta de desenvolvimento sustentável já se fazia presente nas discussões desde a década de 1970. No entanto, é a partir do Relatório de Bruntland que este conceito se torna um marco nas discussões ambientais.

5 Disponível em: <http://www.pac.gov.br/sobre-o-pac>. Acessado em 07/01/2016. http://www. planejamento.gov.br/servicos/faq/pac-programa-de-aceleracao-do-crescimento/visao-geral/ qual-a-diferenca-entre-pac1-e-pac2, . Acessado em 28/06/2017.

6 Conferência das Nações Unidas sobre o Desenvolvimento Sustentável, ocorrida em julho de 2012, 20 anos depois da Eco 92 (Conferência das Nações Unidas sobre o Meio Ambiente) ocorrida em 1992.

7 Este tópico é resultado do aprofundamento da discussão inicialmente desenvolvida no artigo A Terra, o homem e a luta quilombola (ROCHA e SILVA, 2013).

8 Essa é uma fala que leva a uma discussão polêmica dentro dos estudos de saberes tradicionais, pois a ocorrência de biopirataria é uma realidade constatada por muitos pesquisadores. A indústria da biotecnologia usa dos saberes tradicionais como forma de aumentar a identificação das propriedades medicinais em mais de $400 \%$. A biopirataria ocorre quando recursos ou saberes tradicionais associados à biodiversidade são acessados sem respeitar princípios da Convenção da Diversidade Biológica, que envolve a soberania do Estado, o consentimento e aviso prévio sobre a intenção da pesquisa ao país que será investigado, além do rateio dos benefícios obtidos pela pesquisa (SANTILLI, 2005).

9 Para Zhouri e Oliveira, o lugar seria o espaço sobre o qual recai a identidade; é o suporte para o sujeito "ser no mundo" (2010, p.445).

10 Posse e propriedade para o Direito são conceitos distintos, sendo o primeiro o exercício de alguns dos poderes inerentes à propriedade (sejam eles plenos ou não) e o segundo é aquele que pode usar, gozar, dispor e reaver o bem de quem o possua ou detenha. 
11 SANTOS (2008) faz uma nota a respeito dessa informação, falando que os EUA desde a década de 60 dá grandes exemplos de ter incorporado o progressismo, sendo considerada a pátria mãe do ativismo judicial.

12 Graduado em Letras pela UNB, Mestre em Antropologia Social pela UNB e Doutor em Antropologia pela USP. Professor aposentado Associado do Departamento de Antropologia da FFCH / UFBA. Professor Participante do Programa de Pós-Graduação em Antropologia da UFBA, de que foi um dos fundadores e o primeiro coordenador. Membro da Associação Brasileira de Antropologia, da SBPC, da Sociedade Brasileira de Estudos Clássicos e da Sociedade Brasileira de Etnobiologia e Etnoecologia. Membro fundador do Grupo de Pesquisa "Encruzilhada dos Saberes". Fundador e Coordenador do Grupo Hermes de Pesquisa e Promoção Social e do Movimento Vozes de Salvador. Membro do Fórum "A cidade também é nossa", por duas vezes seu coordenador. Membro titular do Conselho de Cultura do Estado da Bahia e Presidente de sua Câmara de Patrimônio. Membro fundador de Koinonia Presença Ecumênica e Serviço. Produção principal em Antropologia da Religião, Antropologia das Sociedades Clássicas, Etnobotânica, Teoria Antropológica. Tradutor de textos científicos e literários. Escritor premiado três vezes em concursos nacionais de literatura, com obras de ficção (conto, novela). Membro da Academia de Letras da Bahia.

13 Livros publicados: A Devoção do Diabo Velho, A Mais Antiga Epopéia do Mundo: a Gesta de Gilgamesh, Águas do Rei Dois estudos Afro-brasileiros, Hino homérico IV - a Hermes, Hinos Órficos, O Encantamento de Sua Santidade Cancão de Fogo, O Mundo das Folhas, Os Olhos Negros do Brasil, O Simbolismo da Cultura Rumores de Festa: o sagrado e o profano na bahia, Um tumulto de asas Apocalipse no Xingu, Veredas: Antropologia Infernal.

14 SERRA, O. J. T. . Monumentos negros: uma experiência. Afro-Ásia, Salvador - Bahia, v. 33, n. 00, p. $169-206,2006.2$

15 SERRA, O. J. T. . Laudo antropológico - Ilê Axé Iyá Nassô Oká, Terreiro da Casa Branca do Engenho Velho. https:/ / ordepserra.wordpress.com/estudos/laudos/. Ùltimo acesso 01.08.2018.

\section{REFERÊNCIAS}

ALIER, Joan Martínez. O Ecologismo dos Pobres: conflitos ambientais e linguagem de valoração. São Paulo: Contexto, 2009, p. 21-39.

ALMEIDA, Antonio. Concepções Ambientalistas dos professores suas implicações em Educação Ambiental. Tese de doutoramento inédita, Universidade Aberta, Lisboa, 2005.

ALONSO, Margarita Flórez. Proteção do conhecimento tradicional? In: SANTOS, Boaventura de Sousa (Org.). Semear outras soluções: os caminhos da biodiversidade e dos conhecimentos rivais. Rio de Janeiro: Civilização Brasileira, 2005.

BALLESTRIN, Luciana. América Latina e o giro decolonial. Revista Brasileira de Ciência Política, n¹1. Brasília, maio - agosto de 2013, pp. 89-117.

BENJAMIN, Antonio Herman. A natureza do direito brasileiro: coisa, sujeito ou nada disso. In: Revista do Programa de Pós-Graduação em Direito da UFC. Vol. 31. 2011. Disponível em: <http://periodicos. ufc.br/index.php/nomos/article/view/398>. Acessado em: 13/03/2016

BRASIL. Constituição da República Federativa do Brasil. 1988.

BRASIL. Decreto $\mathbf{n}^{\mathbf{0}}$ 6.040, de 7 de fevereiro de 2007. Institui a Política Nacional de Desenvolvimento 
Sustentável dos povos e comunidades tradicionais.

BRUNDTLAND, G. H. (Org.). Nosso futuro comum. Rio de Janeiro: FGV, 1987

DECLARAÇÃO de Estocolmo sobre o Meio Ambiente Humano, 1972. Disponível em: <www.mma. gov.br/estruturas/agenda21/_arquivos/estocolmo.doc>. Acessado em: 22/01/2016

DIEGUES, Antonio Carlos Sant'ana. Etnoconservação - Novos Rumos para a Conservação da Natureza. 1. ed. São Paulo: Nupaub e HUCITEC, 2000. v. 1.

DIEGUES, Antonio Carlos Sant'ana. O mito moderno da natureza intocada. $6^{\text {a }}$ Ed. Ampliada - São Paulo: Hucitec: Nupaub-USP/CEC, 2008.

GASPAR, Pedro Portugal. O estado de emergência ambiental. Dissertação de Mestrado. Coimbra: Almedina, 2005.

GOHN, Maria da Glória. Movimentos sociais na contemporaneidade. In: Revista Brasileira de Educação. N. 47. Vol. 16, 2011, p. 333-361.

GRAMSCI, Antonio. Cadernos do Cárcere: Introdução ao estudo da filosofia, a filosofia de Benedetto Croce. Vol. 1. Tradução Carlos Nelson Coutinho. Rio de Janeiro, Civilização Brasileira, 1999.

GROSFOGUEL, Para descolonizar os estudos de economia política e os estudos pós-coloniais: transmodernidade, pensamento de fronteira e colonialidade global". Revista Crítica de Ciências Sociais, n. 80, 2008, p. 115-147.

LEFF, Enrique. Saber ambiental: sustentabilidade, racionalidade, complexidade, poder. 5 ed. Petrópolis, RJ: Vozes, 2001.

MOL, A. P. J., and G. SPAARGAREN. Environment, modernity and the Risk Society: The apocalyptic horizon of environmental reform. Int. Sociol. 8, 1993, p. 431-459.

MARTINS, Andreza. Conflitos ambientais em unidades de conservação: dilemas da gestão territorial no Brasil. Revista bibliográfica de geografia y ciências sociales Universidad de Barcelona. Cuadernos Críticos de Geografia Humana, v. 17, n. 989, 2012. Disponível em: <http://www.ub.edu/geocrit/b3w-989. htm\#_edn4>. Acessado em: 25/03/2017.

ROCHA, Julio Cesar de Sá da. Direito ambiental do trabalho. 2 ed. São Paulo: Atlas, 2013.

ROCHA, Julio Cesar de Sá da. Direito, grupos étnicos e etnicidade: reflexões sobre o conceito normativo de povos e comunidades tradicionais. In: ROCHA, Julio Cesar de Sá da; SERRA, Ordep. Direito ambiental, conflitos socioambientais e comunidades tradicionais. Salvador: Edufba, 2015, p. 13-29.

ROCHA, Julio Cesar de Sá da; SILVA, Roberta Neri. A terra, o homem e a luta quilombola. Revista Contorno. Salvador, Museu de Arte Moderna da Bahia: Vol. 1, No 2, 2013, p. 42-51.

SANTILLI, Juliana. Socioambientalismo e novos direitos: proteção jurídica à diversidade biológica e cultural. São Paulo: Peirópolis, 2005.

SANTOS, Boaventura de Sousa. A Gramática do Tempo: para uma nova cultura política [Para um novo senso comum. A ciência, o direito e a política na transição paradigmática, Volume IV]. Porto: Edições Afrontamento, 2006. 
SANTOS, Boaventura de Sousa. Para uma revolução democrática da justiça. Cortez, 2008.

SANTOS, Boaventura de Sousa. Rio + 20: As críticas. Revista Carta Maior, 08/02/2012. Disponível em: <http:/ / www.cartamaior.com.br/?/Coluna/Rio-20-as-criticas/19497>. Acessado em 10/01/2016.

SERRA, O. J. T. . Monumentos negros: uma experiência. Afro-Ásia, Salvador - Bahia, v. 33, n. 00, p. 169206, 2006.2.

SERRA, O. J. T. . Raça/cor, etnia, desigualdade e conflito no Brasil. Revista Tempo e Presença, Rio deJaneiro, v. 339, n. 00, p. 18-28, 2005.

SERRA, O. J. T. . Candomblé e Intolerância religiosa. Revista Tempo e Presença, Rio de Janeiro, v. 00, n. Ano 24, p. 24-25, 2002.

SERRA, O. J. T. . Obá do Cobre: em defesa de um território Negro. Cultura Vozes, Petrópolis, v. 95, n. 00, p. 34-44, 2001.

SERRA, O. J. T. . Monumentos Negros. Revista Tempo e Presença, Rio de Janeiro, v. 00, n. A 23, p. 22-26, 2001.

SERRA, O. J. T. . No Caminho de Aruanda: A Umbanda Candanga Revisitada. Afro-Ásia, Salvador Bahia, v. 25-26, n. 0, p. 215-256, 2001.

file

SERRA, O. J. T. Antropologia nas Encruzilhadas:Que é feito da Etnociência? Algumas reflexões teóricas a partir de pesquisas sobre Etnomedicina e Etnobotânica no mundo do candomblé.. Revista de Ciências Sociais (UFC), Fortaleza, v. 32, n. 1/2, p. 120-130, 2001.

SERRA, O. J. T. . Laudo antropológico - Ilê Axé Iyá Nassô Oká, Terreiro da Casa Branca do Engenho Velho. https://ordepserra.wordpress.com/estudos/laudos/. Ùltimo acesso 01.08.2018.

SERRA, O. J. T. . Laudo antropológico - Terreiro do Bogum, Zoogodô Bogum Malê Rundó. https://ordepserra.wordpress.com/estudos/laudos/. Último acesso 01.08.2018

SERRA, O. J. T. Laudo antropológico - Terreiro do Bate Folha. https://ordepserra.wordpress.com/estudos/laudos/. Último acesso 01.08.2018.

SERRA, O. J. T. . Laudo antropológico - Terreiro do Gantois, Ilê Axé Iá Omin Iamassê. https:/ /ordepserra.wordpress.com/estudos/laudos/. Último acesso 01.08.2018.

TRINDADE, Antonio Cançado. Direitos Humanos e meio-ambiente: paralelo dos sistemas de proteção internacional. Porto Alegre: S.A. Fabris Editor, 1993.

ZHOURI, Andréa; LASHEFSKI, Klemens; PEREIRA, Doralice B. (orgs.). A Insustentável Leveza da Política Ambiental. Belo Horizonte: Autêntica, 2005.

ZHOURI, Andréa; OLIVEIRA, Raquel. Quando o lugar resiste ao espaço: colonialidade, modernidade e processos de territorialização. In: ZHOURI, Andréa; LASCHEFSKI, Klemens; (Org.). Desenvolvimento e conflitos ambientais. Belo Horizonte: Editora UFMG, 2010. 